\title{
O problema do lançamento oblíquo no Ensino de Física com abordagem na programação de computadores
}

\author{
The problem of the oblique launch in the Teaching of Physics with an \\ approach in computer programming
}

\section{El problema del lanzamiento oblicuo en la Enseñanza de la Física con enfoque de programación por computadora}

Marcos Luis Cassal ${ }^{1}$; Silvia Maria de Aguiar Isaia²; Gilberto Orengo ${ }^{3}$

\section{RESUMO}

Um dos assuntos que tem despertado o interesse e a discussão pela comunidade acadêmica da área de ensino no Brasil é o Ensino de Física. O componente curricular da Física é caracterizado como difícil, desinteressante e que consequentemente apresenta dificuldades no processo de ensino e aprendizagem. Uma das possibilidades de modificar este cenário é o desenvolvimento de aulas com atividades experimentais com o uso de novas tecnologias e recursos computacionais. A questão norteadora para esta investigação foi: Como a programação de computadores pode ajudar nos processos de ensino e aprendizagem do problema do lançamento oblíquo? Este trabalho apresenta uma nova alternativa para as aulas de Física com a construção de programas computacionais, pelos próprios estudantes, aplicados na simulação de fenômenos físicos. O conteúdo abordado fez referência ao problema do lançamento oblíquo. A teoria de aprendizagem que embasou o estudo foi a Teoria dos Campos Conceituais. Os resultados obtidos foram satisfatórios, apontando que a programação de computadores pode ser utilizada como um recurso didático nos processos de ensino e aprendizagem da Física.

Palavras-chave: Ensino Médio; Teoria dos Campos Conceituais; Python; Vergnaud.

\begin{abstract}
One of the subjects that has aroused interest and discussion by the academic community in the area of education in Brazil is the Teaching of Physics. Physics' curricular component is characterized as difficult, uninteresting and consequently the teaching and learning process presents difficulties. One of the possibilities to modify this scenario is the development of classes with experimental activities using new technologies and computational resources. The guiding question for this investigation was: How can computer programming help in the teaching and learning processes of the oblique launching problem? This work presents a new alternative for Physics classes with the construction of computer programs, by the students themselves, applied in the simulation of physical phenomena. The content covered referred to the problem of oblique launching. The learning theory that supported the study was the Conceptual Fields Theory. The results obtained were satisfactory, pointing out that computer programming can be used as a didactic resource in the teaching and learning processes of Physics.
\end{abstract}

Keywords: High school; Conceptual Field Theory; Python; Vergnaud.

${ }^{1}$ Graduado em Informática, Mestre em Computação e Doutor em Ensino de Ciências e Matemática. Professor no Colégio Politécnico da Universidade Federal de Santa Maria (UFSM), Santa Maria/RS - Brasil. E-mail: cassal@politecnico.ufsm.br

${ }^{2}$ Licenciada e Mestra em Filosofia e Doutora em Educação. Professora e Pesquisadora do Programa de PósGraduação em Ensino de Ciências e Matemática (PPGECIMAT) da Universidade Franciscana (UFN), Santa Maria, RS - Brasil. E-mail: silviamariaisaia@gmail.com

${ }^{3}$ Licenciado e Mestre em Física e Doutor em Engenharia Mecânica. Professor e Pesquisador do Programa de Pós-graduação em Ensino de Ciências e Matemática (PPGECIMAT) da Universidade Franciscana (UFN), Santa Maria/RS - Brasil. E- mail: g.orengo@gmail.com 


\section{RESUMEN}

Uno de los temas que ha despertado el interés y la discusión de la comunidad académica en el área de la educación en Brasil es la Enseñanza de la Física. El componente curricular de la Física se caracteriza por ser difícil, poco interesante y que, en consecuencia, presenta dificultades en el proceso de enseñanza y aprendizaje. Una de las posibilidades para modificar este escenario es el desarrollo de clases con actividades experimentales utilizando nuevas tecnologías y recursos computacionales. La pregunta orientadora de esta investigación fue: ¿Cómo puede ayudar la programación de computadoras en los procesos de enseñanza y aprendizaje del problema de lanzamiento oblicuo? Este trabajo presenta una nueva alternativa para las clases de Física con la construcción de programas informáticos, por parte de los propios alumnos, aplicados en la simulación de fenómenos físicos. El contenido cubierto se refería al problema del lanzamiento oblicuo, considerando la situación ideal (sin fricción) y también para una con resistencia al aire viscoso. La teoría del aprendizaje que apoyó el estudio fue la Teoría de Campos Conceptuales. Los resultados obtenidos fueron satisfactorios, señalando que la programación informática se puede utilizar como recurso didáctico en los procesos de enseñanza y aprendizaje de la Física.

Palabras clave: Escuela secundaria; Teoría de Campos Conceptuales; Python; Vergnaud.

\section{INTRODUÇÃO}

Sabe-se das dificuldades de alguns estudantes na compreensão dos conceitos trabalhados em Física, o que resulta, muitas vezes em altos índices de reprovação (OLIVEIRA, 2016; MOREIRA, 2017). A identificação desse problema desperta debates entre pesquisadores que buscam alternativas que possam vir a melhorar tal situação. Os resultados encontrados com a realização de pesquisas no Ensino de Física mostram que o processo de ensino e aprendizagem apresenta sérios problemas, entre eles, a utilização de metodologias que não são mais adequadas para a preparação, com qualidade, dos estudantes que hoje são educados (MOREIRA, 2017). O foco do Ensino de Física está centrado na memorização, aplicação de equações e na preparação dos estudantes para a realização de exames e concursos (SOUSA, 2015).

Um dos propósitos esperados pelo ensino da Física no Ensino Médio é despertar nos estudantes o espírito questionador, a vontade de investigar e interpretar os fenômenos naturais e assim poder proporcionar uma melhor compreensão do universo. Consequentemente esse processo também contribuirá com a formação de uma cultura científica (CORAL; FILHO, 2011).

O uso de recursos tecnológicos pode ser uma boa opção, tornando as aulas mais atrativas e cativantes. Usar recursos tecnológicos que possam mostrar e ajudar na compreensão de fenômenos físicos pode ser uma alternativa interessante e que favoreça o processo de ensino aprendizagem (SOUSA, 2015).

O computador pode ser usado como uma ferramenta de ensino que tem a capacidade de transformar a informação em conhecimento. Utilizar o computador em aulas de Física, na simulação de experimentos, indica uma possibilidade de transformação nas atividades de ensino deste componente curricular. Uma alternativa inovadora para as aulas experimentais é proposta, com a realização de atividades práticas computacionais, nas quais os estudantes possam atuar como construtores, por meio do desenvolvimento de simulações de experimentos físicos, mediante implementações de programas de computador, na intensão de complementar o processo de ensino e aprendizagem.

Este trabalho divulga os resultados parciais de uma tese de doutorado, que teve o propósito de apresentar uma alternativa inovadora para as aulas experimentais, com a realização de atividades práticas computacionais. Para todos os eventos físicos solicitou-se aos estudantes, o desenvolvimento 
de programas na linguagem Python. As situações foram apresentadas na forma de enunciados que evidenciaram dados de um problema específico. Porém, a solicitação foi para que fossem desenvolvidos programas que generalizassem a situação anunciada, isto é, que oferecessem a possibilidade de simular outros dados envolvendo os conceitos relacionados, além de permitir a realização de testes e experimentos variados para cada problema/experimento. São demonstrados os resultados obtidos a partir de uma atividade que apresenta uma resposta relacionada a um problema com composição de movimentos no plano. $O$ instrumento de análise foi o lançamento oblíquo de um objeto, tanto para uma situação ideal (sem atrito), como para uma com resistência viscosa do ar.

A teoria de aprendizagem que embasou a pesquisa foi a Teoria dos Campos Conceituais, portanto, apresenta-se a proposta de aplicação da teoria de Vergnaud no processo de ensino e aprendizagem da programação de computadores. A pesquisa foi de cunho qualitativo e o levantamento de dados baseou-se nos resultados obtidos pela implementação de experimentos virtuais, na forma de programas computacionais com enunciados específicos envolvendo situações relacionadas a assuntos da Física.

O artigo está organizado com a seguinte estrutura: na próxima seção é exposta a Teoria dos Campos Conceituais de Gérard Vergnaud, posteriormente é abordado o Ensino de Física no Ensino Médio. A importância da programação no Ensino Médio é o assunto da seção Programação de Computadores, que é seguida da metodologia do trabalho. A seção Resultados e discussões expõe o desenlace da pesquisa com a observância da Teoria de Vergnaud nos campos conceituais da Física e da Programação de computadores para o problema do lançamento oblíquo. O trabalho encerra-se com as conclusões e referências bibliográficas.

\section{TEORIA DOS CAMPOS CONCEITUAIS}

A teoria apresentada por Vergnaud foi desenvolvida com o propósito de compreender os problemas de desenvolvimento no interior de um mesmo campo de conhecimento, procurando propiciar uma estrutura às pesquisas sobre atividades cognitivas complexas, em especial com referência às aprendizagens científicas e técnicas. A ideia principal é apresentar uma teoria geral para o desenvolvimento, que procura relacionar a evolução do aprendiz com as tarefas que esse sujeito é levado a resolver. A cognição tem como cerne a conceitualização, que é um processo longo e que requer uma diversificação de situações.

A diversificação de situações cumpre um papel importante na conceitualização, fornece uma base para o sujeito testar seus modelos explicativos em contextos diversos, enriquecendo tais modelos ou reformulando-os. Por esse motivo é importante diversificar as atividades de ensino, permitindo ao sujeito a aplicação do conceito em diferentes situações e que possa fazer a integração entre as partes e o todo. Existe a necessidade de uma visão integradora do conhecimento, pois uma visão generalizante pode contribuir para uma melhor apropriação deste saber pelo sujeito. Trabalhando os conceitos de um dado campo conceitual com profundidade e durante um intervalo de tempo suficiente, o aprendiz poderá construir uma visão integradora do que está aprendendo.

A Teoria dos Campos Conceituais (TCC) é complexa, compreende em uma única perspectiva teórica o desenvolvimento de situações, conceitos e teoremas necessários para concretizar eficientemente 
tais situações e dos símbolos e palavras que descrevem de maneira eficaz esses conceitos e operações (VERGNAUD; MOREIRA, 2017).

Segundo Vergnaud (2017), a Teoria dos Campos Conceituais surgiu de estudos relacionados à didática da matemática e procura disponibilizar uma análise do processo de aprendizagem dos conceitos. É uma teoria psicológica e didática que tenta levar em conta a questão do desenvolvimento e a aprendizagem dos conhecimentos em longo prazo. As ideias básicas que fundamentam a TCC são:

(a) Um conceito adquire sentido em função da multiplicidade de problemas aos quais responde;

(b) Os conceitos não funcionam isoladamente, mas sim vinculados uns aos outros, numa ampla e complexa rede;

(c) A aprendizagem de todas as propriedades e relações que envolvem tais conceitos acontece por meio de uma longa história, entrelaçada por uma série de filiações e rupturas;

(d) Um conceito não remete apenas à sua possibilidade de funcionar na resolução de problemas.

O principal objetivo de um campo conceitual é apontar subcampos da experiência, envolvendo as ideias de situação e conceito. Um conceito não se desenvolve em uma única categoria de situações, mas em uma variedade, que às vezes pode ser muito ampla. Não se analisa uma situação com base em um único conceito, mas sim em vários. Essa construção e apropriação dos conceitos e aspectos das situações é um processo demorado que se estende por um longo período (VERGNAUD; MOREIRA, 2017).

\section{ENSINO DE FÍSICA}

A BNCC adotou um processo de aprendizagem baseado em competências e habilidades, preocupando-se em capacitar os estudantes para os desafios da vida cotidiana, focado no desenvolvimento e preparação dos alunos para as instigações do mundo (BRASIL, 2018).

As ações de aprendizagem definidas na BNCC estabelecem o desenvolvimento de competências, assinalando que os alunos devem "saber" (considerando a constituição de conhecimentos, habilidades, atitudes e valores) e, sobretudo, devem "saber fazer" considerando a mobilização desses conhecimentos, habilidades, atitudes e valores para resolver demandas complexas da vida cotidiana, do pleno exercício da cidadania e do mundo do trabalho (BRASIL, 2018). Essas competências se relacionam de diversas maneiras, logo, deve-se pensar em desenvolver um trabalho integrador, que propicie uma inter-relação com as habilidades propostas no documento orientador da BNCC.

A área de Ciências da Natureza e suas Tecnologias engloba, com um olhar articulado, as áreas da Biologia, Física e Química. A BNCC tem a pretensão de que os estudantes aprendam a aplicar os conhecimentos científicos desta área na vida cotidiana. Os conhecimentos conceituais são sistematizados em leis, teorias e modelos, eles constituem a base para o processo de ensino e aprendizagem dos estudantes, no sentido de estimular a investigação, conduzindo a análises e discussões de situações-problema.

A Física trabalha com modelos científicos complexos e essa complexidade, muitas vezes, dificulta a contextualização por parte dos alunos e consequentemente pode ocorrer um bloqueio cognitivo, 
dificultando a assimilação, seguido de uma rejeição e o desinteresse pelo estudo. Outro aspecto que precisa ser considerado é com relação ao formalismo matemático que faz parte dos estudos deste componente curricular, também causando certo distanciamento dos modelos utilizados para estudar a natureza. O conjunto destes fatores acaba prejudicando o processo de ensino aprendizagem, que pode ocasionar um baixo rendimento nas avaliações, o que passa a ser mais um fator agravante no desinteresse e motivação para estudar a Física. Com base nos pontos apresentados pode-se classificar este componente curricular como difícil e desagradável, logo, os estudantes acabam estudando a Física com o propósito de terem condições de prestarem exames (SOUSA, 2015).

O tema Ensino tem despertado discussões e o interesse de muitos pesquisadores, na busca de ações que têm o propósito de melhorar efetivamente a sua qualidade. Dentre as linhas de pesquisa inserese o ensino de Física e alguns trabalhos desta área buscam a superação das limitações das metodologias tradicionais, consideradas ultrapassadas e pouco motivadoras. Os relatos apresentados indicam que as aulas de Física acabam se resumindo em aplicação de equações e memorização, dificultando a relação por parte dos estudantes dos conceitos expostos a fatores que ocorrem na vida diária, dificultando o aprendizado e principalmente a não identificação da importância de se aprender os conceitos deste componente curricular.

O ensino e a aprendizagem de Física têm graves problemas. O modelo de aula expositiva e avaliação via prova escrita, como metodologia majoritária ou exclusiva de ensino, tem se mostrado desmotivador para os estudantes. A aula tradicional não dá ao aluno papel ativo no processo de aprendizagem. Essa situação dificulta o ensino e a aprendizagem e torna o envolvimento cognitivo dos alunos um desafio ainda maior para o professor (SANTOS, 2016, p. 17).

Segundo Porto (2015), o ensino de Física vem sendo ministrado com aulas expositivas que trabalham leis, conceitos e equações matemáticas, com assuntos desvinculados da realidade. Tudo isso faz com que a Física se torne distante do mundo vivido tanto dos professores como dos alunos, o que dificulta ainda mais a sua compreensão. Os alunos estão cada vez mais desinteressados, preocupam-se apenas com a nota e com a aprovação, os assuntos estudados são logo esquecidos e aumentam os problemas deste componente curricular.

A Física é ensinada e desenvolvida, geralmente, com uma didática baseada em aulas teóricas e listas de exercícios, centrada no docente e não no aluno; o que vale é a resposta correta, não o questionamento, a pergunta. O resultado é conhecido: os alunos decoram as equações, as respostas corretas, e não gostam de Física. A integração da Física com as outras áreas é importante e precisa ser considerada (SCHITTLER, 2015).

Os conteúdos do componente curricular de Física, no Ensino Médio, em geral, continuam sendo abordados e avaliados de um modo excessivamente formal, restringindo os estudantes a utilizarem os conhecimentos adquiridos em situações-problema, criando um distanciamento entre os conhecimentos de Física e a vivência fora da sala de aula. Essa forma de aprender e ensinar não é atrativa e acaba "ocultando" a verdadeira importância em se aprender Física, além de reforçar a concepção de que o conhecimento científico é sinônimo de verdade definitiva e permanente. A Ciência não é vista como uma construção humana e o seu progresso parece resultar da mera acumulação de sucessivos descobrimentos e constante aperfeiçoamento de teorias. Esses aspectos têm sido estudados na área do ensino de Física e as pesquisas tem mostrado que estratégias didáticas precisam ser investigadas para privilegiar uma reflexão crítica dos conteúdos abordados, tanto por alunos como por professores (BRANDÃO, 2012). 
A inserção de novos recursos educacionais nas aulas, que possibilitem a realização de situações que envolvam atividades experimentais, nas quais o professor atue como mediador e não como transmissor do conhecimento, pode favorecer uma maior interação na sala de aula. Se as atividades forem divididas entre os colegas, inicia-se um processo de compartilhamento de ideias, dúvidas e divergências, possibilitando um trabalho coletivo, que por sua vez facilita a relação dos alunos com situações que vão favorecer o entendimento do conceito.

É preciso despertar nos estudantes o interesse pelo aprendizado, e uma alternativa é reduzir as aulas exclusivamente expositivas e inovar com aulas dinâmicas e criativas. É necessário fazer uma reestruturação no ensino de Física do Ensino Médio, com a realização de atividades práticas e experimentais, que facilitem a aprendizagem.

Aprender Física é aprender como os fenômenos naturais ocorrem em seus aspectos mais gerais, esse aprendizado ajuda o ser humano a entender melhor o mundo e consequentemente propor melhorias na qualidade de vida e da natureza. Na escola, os alunos aprendem a Física por diferentes métodos, com instruções tradicionais e também com orientações facilitadas pelo uso de tecnologias. Estudos indicam que a melhor maneira para aprender a Física é envolver o aluno com a pesquisa e 0 experimento (WONGWATKIT; PANJABUREE, 2017).

\section{PROGRAMAÇÃO DE COMPUTADORES}

A computação abrange processos sistemáticos que exploram o raciocínio lógico. Estes processos atualmente são trabalhados predominantemente no Ensino Superior ou em cursos técnicos e deveriam ser explorados desde o Ensino Básico, pois melhoram a capacidade de dedução e conclusão de problemas (MELO; COSTA; BATISTA, 2013). São componentes curriculares básicos, ministrados nos primeiros semestres dos cursos e contemplam a formação basilar dos estudantes.

Analisando o papel crescente da Tecnologia da Informação e da Comunicação (TIC) na atualidade, a programação pode ser considerada essencial nessa reestruturação do ensino, por trabalhar com competências como: pensamento crítico, capacidade de tomar decisão, inovação, comunicação, análise, capacidade de resolver problemas, interpretação, entre outras. Segundo Scaico et al. (2013), a proximidade com a programação pode despertar nos estudantes o interesse em estudar as tecnologias que eles estão habituados a manusear. A grande maioria dos estudantes gasta boa parte do dia com jogos e redes sociais, sendo consumidores de informações geradas pela tecnologia, mas não sabem como produzir conhecimento e como utilizar o potencial disponível pelas tecnologias.

É preciso repensar quais os conteúdos que devem ser ensinados e desenvolvidos nas escolas, procurando desenvolver nos estudantes a capacidade de criar e se expressar, preparando-os para a fluência em Tecnologia da Informação. Ensinar programação de computadores pode ser o início deste processo (RESNICK, 2012). Pozzebon et al. (2013) credita à Tecnologia da Informação e à Internet as principais razões para introduzir a programação de computadores nas escolas. Os autores consideram que esses fatores são entusiastas e podem despertar o interesse pela programação. Diante dessa situação é preciso se preocupar com a possibilidade de proporcionar aos estudantes, a habilidade de trabalhar com computadores e saber explorar o potencial que essa tecnologia pode oferecer, mostrando que é possível usar o computador como uma ferramenta que venha auxiliar no seu crescimento intelectual e não somente na diversão e entretenimento. 
Aprender uma linguagem de programação é uma tarefa desafiadora. Todavia, tornar o ensino de programação mais acessível para um maior número de indivíduos, pode vir a estimular muitas capacidades cognitivas, possibilitando ao estudante a aplicação de técnicas de programação na resolução de diversos outros tipos de problemas, nas mais distintas áreas.

O estudo do lançamento oblíquo com o uso de simulações computacionais é um assunto com relevância para a componente curricular da Física no Ensino Médio, abordado em outras pesquisas desenvolvidas e divulgadas pela comunidade acadêmica, como nos trabalhos de Anjos, Freitas e Neto (2016), Alves et al. (2019), Germano (2016) e Vidal e Fontoura (2020).

O trabalho de Anjos, Freitas e Neto (2016) teve o objetivo de mostrar a utilização do Scratch combinado com o jogo Angry Birds Space no processo de aprendizagem/ensino do lançamento de projéteis envolvendo o conceito de gravidade. A pesquisa de Alves et. Al. (2019) propôs a utilização da plataforma Scratch na construção de jogos para simular fenômenos físicos e relacioná-los a conteúdos da Física, aplicando à cinemática no estudo do movimento bidimensional.

A dissertação desenvolvida por Germano (2016) verifica a adequação e a compreensão dos fenômenos físicos relacionados à cinemática e dinâmica por meio da produção e aplicação de simulações virtuais modeladas no software Algodoo. O artigo de Vidal e Fontoura (2020) descreve a utilização de programas que abordam o lançamento oblíquo, pêndulo simples e velocidade de moléculas de gases em simulações 3D, nos quais o usuário interage, explorando as variáveis envolvidas para observar as relações de causa e efeito dos fenômenos físicos propostos.

A presente pesquisa se difere das demais principalmente no aspecto de que os próprios estudantes desenvolveram a codificação dos programas, por meio da linguagem de programação Python. Os resultados obtidos mostram que este recurso auxiliou na compreensão de conceitos físicos relacionados ao problema do lançamento oblíquo, além de contribuir com a formação científica dos discentes.

\section{METODOLOGIA}

Esta pesquisa é de cunho qualitativo, a investigação abrange o processo de aprendizagem de alguns conceitos da Física em nível de Ensino Médio, por intermédio da construção de programas computacionais implementados na linguagem de programação Python, sob a luz da Teoria dos Campos Conceituais de Gérard Vergnaud. Com a realização deste trabalho foram desenvolvidos procedimentos de investigação e análise, verificando e entendendo como o tema da pesquisa pode contribuir com o processo de ensino e aprendizagem, vindo a ser um instrumento capaz de apoiar e auxiliar o trabalho conjunto entre professor e estudante na construção do conhecimento.

Foi aplicado o método de estudo de caso de observação, a exploração dos dados ocorreu durante a realização de atividades didáticas que se realizaram em uma Unidade de Educação Básica, Técnica e Tecnológica de uma Universidade Federal, com alunos do Ensino Médio. O problema de pesquisa está alicerçado na Programação de Computadores. Como já mencionado anteriormente, a programação de computadores não faz parte das componentes curriculares que são ministradas no Ensino Médio. Para a realização deste trabalho, foi elaborado e proposto um curso de Formação Inicial e Continuada (FIC) de Programação de Computadores, que ofereceu aos estudantes uma formação básica na área. 
Foi realizada a apresentação da proposta do projeto aos alunos do Ensino Médio da escola e permitida a participação de todos interessados, mediante inscrição prévia. A turma foi fechada com dezenove participantes, todos sem conhecimentos relacionados à programação de computadores. No decorrer do projeto alguns deles optaram por desistir do curso e três estudantes chegaram à conclusão.

Durante o processo de efetivação do curso foram executadas atividades práticas que proporcionaram, aos estudantes, situações empíricas que caracterizaram a resolução de problemas experimentais do componente curricular de Física e que foram solucionadas com a implementação de programas de computador.

O curso se enquadrou no eixo tecnológico de informação e comunicação, teve uma carga horária total de cento e sessenta horas e foi executado em três semestres, em um encontro semanal com duração de quatro horas, no contraturno, efetivado em quarenta encontros.

A atividade descrita no artigo aborda o problema do lançamento oblíquo, com o propósito de que ao ser solucionada, pelos estudantes, eles pudessem apresentar uma resposta referente a um problema com composição de movimentos no plano. $O$ instrumento de análise foi o lançamento oblíquo de um objeto, tanto para uma situação ideal (sem atrito), como para uma com resistência viscosa do ar. A execução da atividade se deu em torno de oito horas.

Os dados representam a base para todo trabalho investigativo, por este motivo é preciso escolher os instrumentos adequados para esta etapa. Os instrumentos elencados para a realização da coleta de dados desta pesquisa seguiram os procedimentos metodológicos do estudo de caso e correspondem a questionários, observações, entrevistas e atividades práticas propostas no formato de programas de computador escritos na linguagem de programação Python.

O motivo que direcionou a adoção da Teoria dos Campos Conceituais neste estudo está associado ao fato de que esta teoria relaciona a evolução do aprendiz de acordo com as tarefas que ele precisa solucionar, tendo a conceitualização como núcleo e requerendo uma grande diversidade de situações. Ao apresentar aos estudantes atividades que os desafiavam a desenvolver programas de computador, se teve a intenção de despertar neles a curiosidade e a inquietação pela busca dos conceitos físicos necessários para a resolução dos problemas, assim como a aplicação correta da lógica de programação e dos comandos adequados da linguagem de programação Python na codificação dos programas. Esses aspectos convergem com a teoria, pois o desenvolvimento de um programa envolve uma diversidade de situações problema.

A teoria de Vergnaud aborda a análise dos conceitos na busca de compreender o desenvolvimento cognitivo e a aprendizagem das competências que dependem da ciência e da técnica, considerando os conteúdos do conhecimento e a análise conceitual do seu domínio, procurando entender como o sujeito aprende em situação. Segundo Grossi (2017), a expectativa de resultados concretos implica na exigência de serem reconhecidos os avanços graduais no processo de aprender. Assim, por meio da Teoria dos Campos Conceituais foi realizada a análise dos dados levantados, procurando concatenar os conteúdos que formam o corpus de análise do trabalho, o Ensino de Física e a Programação de Computadores. 


\section{RESULTADOS E DISCUSSÕES}

O propósito desta atividade foi de que ao ser desenvolvida, pelos estudantes, eles pudessem apresentar uma solução computacional para um problema com composição de movimentos no plano. O problema foi apresentado com o seguinte enunciado:

A análise do lançamento oblíquo de objetos no ar é muito importante e é uma forma de estudarmos a composição de movimentos, neste caso bidimensional. Suponhamos que no tempo igual a zero, que consideraremos o início da análise do movimento, a posição do objeto será:

$$
x(t=0)=y(t=0)=0.0(\text { Equação } 1),
$$

e que neste instante $(t=0)$ as velocidades horizontal e vertical são:

$$
\begin{aligned}
& v_{x}(0)=v_{0} \cos (\theta) \equiv U(\text { Equação } 2), \\
& v_{y}(0)=v_{0} \sin (\theta) \equiv V(\text { Equação } 3),
\end{aligned}
$$

em que $\mathrm{v}_{0}$ é a velocidade inicial do objeto e $\theta$ é o ângulo que a velocidade inicial faz com a horizontal. Como o movimento é no ar, há uma resistência natural ao movimento devido ao arraste do ar, que é representado pela constante positiva $\mathrm{k}$, cuja unidade neste caso específico é $1 / \mathrm{s}$ ou s${ }^{-1}$. Usando estes elementos para o movimento, a solução do problema, no campo gravitacional terrestre $\mathrm{g}$, temos:

$$
\begin{gathered}
x=x(t)=\frac{U}{k}\left(1-e^{-k t}\right)(\text { Equação 4), } \\
y=y(t)=-\frac{g t}{k}+\frac{k V+g}{k^{2}}\left(1-e^{-k t}\right)(\text { Equação } 5),
\end{gathered}
$$

que fornece a trajetória da partícula no ar, por meio do par ordenado $(x ; y)$. Assim, para obtermos a trajetória basta indicarmos valores para o tempo.

1. Desenhe a trajetória do movimento quando temos uma resistência do ar com $k=0.01 \mathrm{~s}^{-1}$, num ângulo de lançamento $\theta=60$ ० e velocidade inicial $v_{0}=600 \mathrm{~m} / \mathrm{s}$.

2. Obtenha a altura máxima que o objeto atinge, e em que instante ocorre esse máximo.

3. Obtenha o alcance máximo horizontal atingido pelo objeto, bem como o intervalo de tempo para ele atingir essa distância.

4. Refaça todos os itens acima para quando podemos desprezar a resistência do ar; e compare os resultados. Aqui é importante perceber que não basta fazer $k=0$, porque teremos um problema de indeterminação nas Equações (4) e (5). Então, é necessário lembrar que neste caso temos:

$$
\begin{gathered}
x=U t(\text { Equação 6), } \\
y=V t-\frac{g t^{2}}{2}(\text { Equação 7). }
\end{gathered}
$$

5. Retornando ao alcance máximo horizontal, uma forma de encontrar o tempo de voo é impondo a condição de y $=0$ na Equação (5). Faça isso e encontre o tempo de voo para o alcance máximo horizontal e compare com o resultado obtido no item 3 .

6. Com o tempo do item anterior, encontre o alcance máximo horizontal e compare com o do item 3. 
Na sequência serão discutidos para o problema do lançamento oblíquo: o campo conceitual da Física e o campo conceitual de um programa em Python.

\subsection{Campo Conceitual da Física para o Problema do Lançamento Oblíquo}

O tema lançamento oblíquo está relacionado com a locomoção num plano de um objeto, no qual deve ser considerado um ângulo $\theta$ com a horizontal (entre $0^{0}$ e $90^{\circ}$ ), originando uma trajetória parabólica. Para que o objeto entre em movimento, é necessária a aplicação de uma força, por meio de um impulso e que não é considerado no estudo, e que dará início ao processo de locomoção, ocasionando dois deslocamentos simultâneos, um na vertical (eixo-y) quando o objeto sobe e desce e outro na horizontal (eixo-x) quando o objeto vai para frente, com a existência de duas velocidades independentes entre si. A combinação destes dois movimentos ocasiona o lançamento oblíquo.

A altura máxima atingida pelo objeto é uma informação importante para a análise, e se a resistência do ar for ignorada, o objeto está sujeito apenas a aceleração da gravidade. Assim, se o projétil estiver subindo, a força gravitacional atuará contra esse movimento e diminuirá a sua velocidade. Por outro lado, se o projétil estiver descendo, a força gravitacional atuará na direção do movimento e aumentará a velocidade do objeto. Nesta movimentação a velocidade vertical vai diminuindo, até ser nula e atingir o ponto máximo, ponto em que ocorre a inversão no sentido do movimento, e na sequência retorna ao solo.

O deslocamento no eixo horizontal, que não está sujeito a aceleração, será com velocidade constante. $\mathrm{E}$, o percurso total indica o alcance máximo, isto é, a distância percorrida pelo objeto entre o ponto de partida e o de chegada. No início do lançamento é preciso considerar a velocidade do objeto, com um ângulo $\theta$ na horizontal.

A Tabela 1 apresenta os elementos que foram identificados na resolução do problema do Lançamento Oblíquo.

Tabela 1 - Campos Conceituais do Lançamento Oblíquo

\begin{tabular}{|c|c|c|c|}
\hline \multirow{2}{*}{ Situação } & \multicolumn{2}{|c|}{ Invariante operatório } & \multirow{2}{*}{$\begin{array}{l}\text { Representação } \\
\text { simbólica }\end{array}$} \\
\hline & Conceitos-em-ação & Teoremas-em-ação & \\
\hline Sem resistência do ar & $\begin{array}{l}\text { Tempo } \\
\text { Ângulo de lançamento } \\
\text { Funções } \\
\text { trigonométricas } \\
\text { Posição da partícula } \\
\text { Velocidade da partícula } \\
\text { Campo gravitacional } \\
\text { terrestre }\end{array}$ & $\begin{array}{l}\text { Intervalo de tempo } \\
\text { Maior que } 0^{0} \text { e menor } \\
\text { que } 90^{\circ} \\
\text { Cosseno } \\
\text { Seno } \\
\text { Horizontal } \\
\text { Vertical } \\
\text { Horizontal - x } \\
\text { Vertical - y } \\
9,83 \mathrm{~m} / \mathrm{s}^{2}\end{array}$ & $\begin{array}{l}\mathrm{te} \Delta \mathrm{t} \\
\theta \\
\cos \\
\sin \\
\mathrm{x} \\
\mathrm{y} \\
\mathrm{V}_{\mathrm{x}} \\
\quad v_{x}(t)=v_{0} \cos (\theta) \\
\mathrm{V}_{\mathrm{y}} \\
v_{y}(t)=v_{0} \sin (\theta) \\
\mathrm{g}\end{array}$ \\
\hline
\end{tabular}




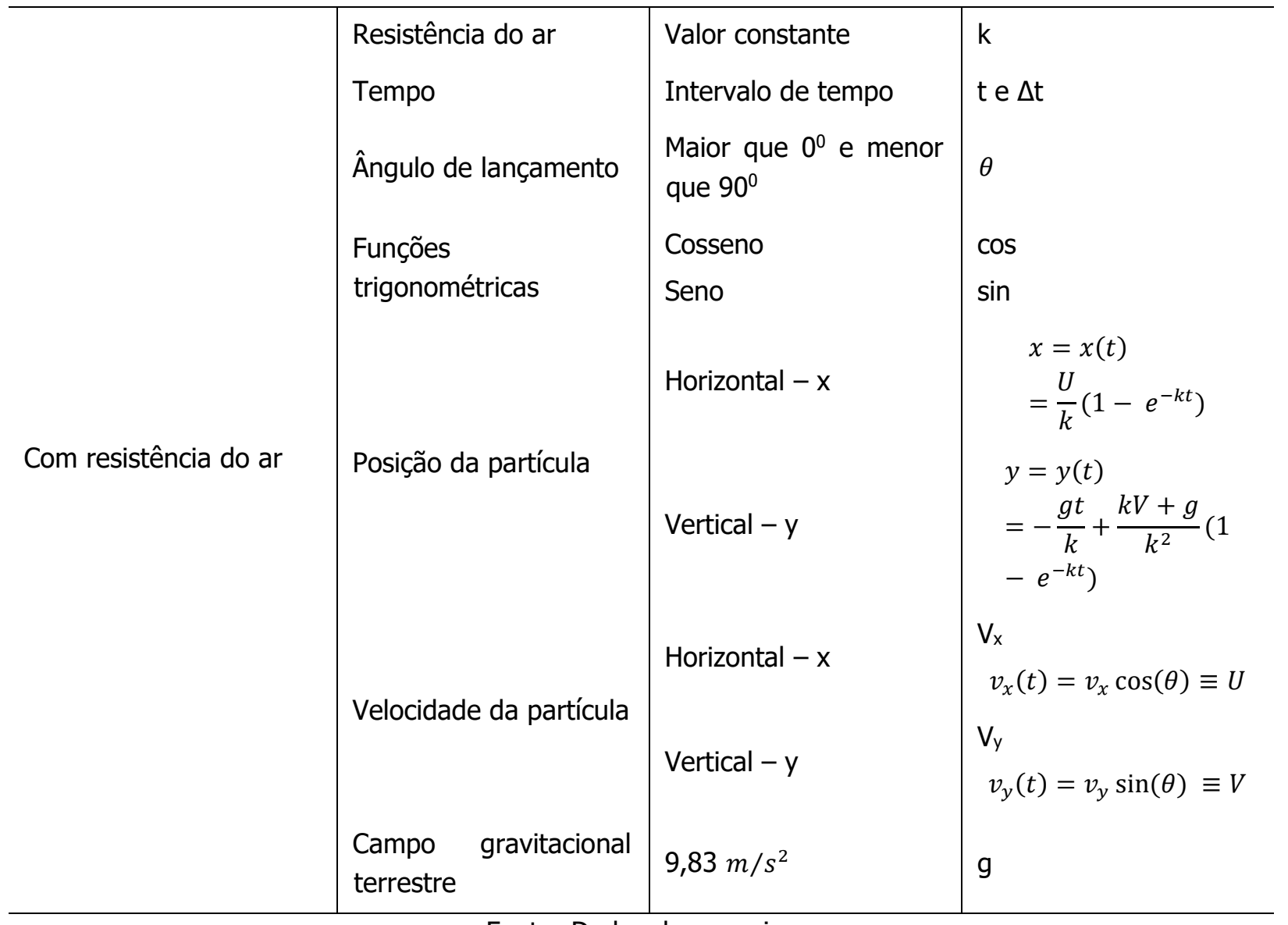

Fonte: Dados da pesquisa

As metas e antecipações orientam a resolução de uma determinada situação. As regras de ação têm a responsabilidade de coordenar a sequência de ações. A construção dos modelos mentais do indivíduo, indicando o que é relevante e apropriado à situação são as funcionalidades dos conceitosem-ação e teoremas-em-ação. As inferências (raciocínio) baseiam-se nas informações obtidas dos invariantes operatórios e determinam as regras e antecipações.

O fenômeno do lançamento oblíquo terá outro comportamento se for levada em consideração a resistência do ar. Nos casos em que um objeto se movimenta por meio de um fluído (gás, líquido ou vapor) existe uma força que se opõe a esse movimento. Nas condições estabelecidas no enunciado da atividade essa movimentação se dá no ar, assim, para estes casos a força opositora é identificada como resistência do ar, cuja representação se dá com a constante k, com unidades $1 / \mathrm{s}_{\text {ou s}}{ }^{-1}$.

É preciso considerar a posição inicial, que determina a localização inicial da partícula, que de acordo com o enunciando, para o início da análise do movimento, por definição será considerada $\mathrm{x}=0 \mathrm{e}$ y $=0$ (teorema-em-ação).

O fator tempo é outro conceito-em-ação presente no lançamento oblíquo, a sua totalidade representa o tempo gasto necessário para que o objeto parta da sua posição inicial, chegue ao ponto mais alto na vertical e retorne ao solo. O valor inicial para o tempo é igual a zero e sua variação será de $\Delta \mathrm{t}=\mathrm{tf}-\mathrm{ti}$.

O ângulo é um conceito-em-ação importante no lançamento oblíquo, é determinado pela inclinação existente em relação a linha horizontal e influencia diretamente na posição do maior alcance do lançamento. Este ângulo deve ser maior que $0^{\circ}$ e menor que $90^{\circ}$. 
O conceito-em-ação Funções trigonométricas é aplicado neste contexto no sentido de que é possível calcular a posição da partícula. Os teoremas-em-ação seno e cosseno do ângulo determinam as coordenadas $\mathrm{x}$ e y do objeto, o $\mathrm{x}$ é definido pelo cosseno do ângulo e o y pelo seno do ângulo.

O campo gravitacional (conceito-em-ação), indica que se deve levar em consideração o valor $9,83 \mathrm{~m} / \mathrm{s}^{2}$ (teorema-em-ação), uma vez que o enunciado do problema indica que o campo gravitacional a ser considerado é o terrestre.

O conceito-em-ação Posição final faz referência ao ponto de maior alcance do objeto lançado, e é a distância percorrida pelo objeto entre os pontos inicial e final.

A segunda situação apresentada, lançamento oblíquo com resistência do ar, evidencia o conceitoem-ação Resistência do ar, que corresponde ao coeficiente $k$ e que referencia a força de resistência entre o objeto lançado e o ar. Este coeficiente é um valor constante, definido e estabelecido pelos valores de referência das unidades de medida dos padrões internacionais.

No lançamento oblíquo com resistência do ar também é preciso calcular a posição da partícula, em função do tempo. As funções trigonométricas (conceito-em-ação), por intermédio do cosseno e do seno do ângulo (teorema-em-ação), e o tempo, permitem calcular as coordenadas x e y da partícula. Esses valores serão aplicados no cálculo da posição da partícula (conceito-em-ação) para as velocidades horizonta e vertical (teorema-em-ação), considerando o coeficiente de resistência do ar.

\subsection{Campo Conceitual de um Programa em Python para o Problema do Lançamento Oblíquo}

As tabelas 2, 3 e 4, estão estruturadas conforme a Teoria dos Campos Conceituais, sendo possível a identificação das Situações, Invariantes Operatórios e Representações Simbólicas. Os conteúdos destas tabelas estão diretamente relacionados com o campo conceitual da programação em Python, que foram elaborados com base no programa escrito pelos estudantes. As numerações das linhas das representações simbólicas correspondem a mesma numeração dos códigos que serão apresentados.

Tabela 2 - Campos Conceituais Programação - Lançamento Oblíquo (1)

\begin{tabular}{|c|c|c|c|}
\hline \multirow{2}{*}{ Situação } & \multicolumn{2}{|c|}{ Invariante operatório } & \multirow{2}{*}{$\begin{array}{l}\text { Representação } \\
\text { simbólica }\end{array}$} \\
\hline & Conceitos-em-ação & Teoremas-em-ação & \\
\hline $\begin{array}{l}\text { A comunicação entre o } \\
\text { usuário e o programa }\end{array}$ & $\begin{array}{l}\text { Campos } \\
\text { Dados de entrada } \\
\text { Caixas de seleção } \\
\text { Caixa de mensagens } \\
\text { Evento } \\
\text { Componentes }\end{array}$ & $\begin{array}{l}\text { Widget Label } \\
\text { Widget Entry } \\
\text { Widget Checkbutton } \\
\text { Widget Messagebox } \\
\text { Click no widget Button }\end{array}$ & $\begin{array}{l}\text { Linhas: } 99 \text { a } 109 \\
\text { Linhas: } 111 \text { a } 123 \\
\text { Linhas: } 128 \text { e } 132 \\
\text { Linha: } 18 \\
\text { Linha: } 125\end{array}$ \\
\hline
\end{tabular}

Fonte: Dados da pesquisa.

A situação Comunicação entre o usuário e o programa, está representada na Figura 1, pela tela inicial do software. Ao examinar a figura é possível perceber que a identificação dos campos se deu com a utilização de widgets Label (teorema-em-ação). São componentes gráficos (conceito-em-ação) que estão sendo utilizados como etiquetas de identificação. 
Figura 1 - Interface inicial do programa

\begin{tabular}{ll}
\hline Lançamento Oblíquo & \multicolumn{1}{c}{ L } \\
Informe a velocidade inicial (m/s): & 600 \\
Infome o ângulo inicial (graus): & 60 \\
Informe o coeficiente de atrito: & 0.01 \\
Informe a gravidade: & 9.80665 \\
\hline Calcular \\
\hline$\Gamma$ Com atrito do ar \\
『 Juntar os gráficos \\
\hline
\end{tabular}

Fonte: Dados da pesquisa

Figura 2 - Identificação dos campos de entrada

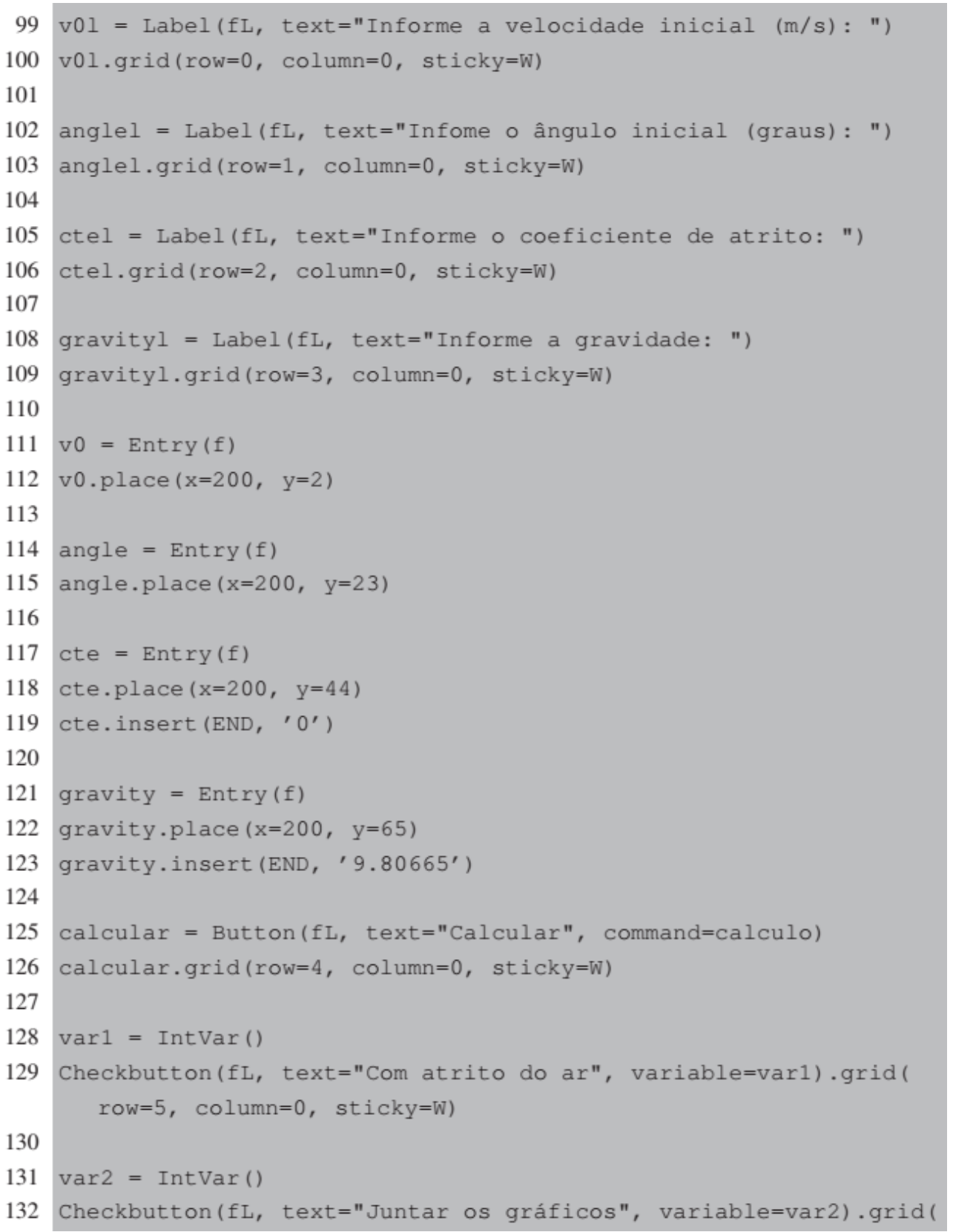

Fonte: Dados da pesquisa.

Para o programa iniciar o processamento da sua funcionalidade será preciso informar inicialmente quatro valores: A velocidade inicial, O ângulo inicial, O coeficiente de atrito e o campo gravitacional. 
Esses quatro campos caracterizam os conceito-em-ação "Dados de entrada", que no código foram implementados com o emprego de widgets do tipo Entry (teorema-em-ação). Além desses campos, também pode-se perceber a existência de duas caixas de seleção (conceito-em-ação), que oferecem ao usuário a possibilidade de contemplar a resistência do ar na simulação e também visualizar as duas trajetórias no gráfico, uma considerando a resistência do ar e outra não.

No trecho de código, apresentado na Figura 2, pode-se conferir as definições das identificações dos campos, das caixas de texto para a digitação de valores de entrada e as opções de escolha nas caixas de seleção, definidas com a utilização de widgets Checkbutton (teorema-em-ação).

A execução do cálculo do lançamento oblíquo ocorrerá quando a ação do usuário for de clicar no componente botão (conceito-em-ação), identificado como "Calcular", ocasionando um evento (conceito-em-ação). Neste momento acontecerá o disparo do evento click (teorema-em-ação), que consequentemente fará a chamada da rotina cálculo. No código da Figura 2, na linha 125, é possível identificar a definição do widget Button (teorema-em-ação), assim como a relação do evento com a chamada da rotina cálculo (instrução command).

A situação Cálculo da trajetória da partícula é apresentada na próxima tabela, juntamente com os invariantes operatórios e as representações simbólicas.

Tabela 3 - Campos Conceituais Programação - Lançamento Oblíquo (2)

\begin{tabular}{|c|c|c|c|}
\hline \multirow{2}{*}{ Situação } & \multicolumn{2}{|c|}{ Invariante operatório } & \multirow{2}{*}{$\begin{array}{l}\text { Representação } \\
\text { simbólica }\end{array}$} \\
\hline & Conceitos-em-ação & Teoremas-em-ação & \\
\hline $\begin{array}{l}\text { Cálculo da trajetória da } \\
\text { partícula }\end{array}$ & $\begin{array}{l}\text { Rotina } \\
\text { Tipos de dados } \\
\text { Conversão entre tipos } \\
\text { Estrutura de dados } \\
\text { composta } \\
\text { Teste condicional } \\
\text { Laço de repetição } \\
\text { Equações }\end{array}$ & $\begin{array}{l}\text { def calculo } \\
\text { float } \\
\text { float() } \\
\text { list vertices_com } \\
\text { list apices } \\
\text { list vertices_sem } \\
\text { if } \\
\text { while } \\
\text { Velocidades horizontal } \\
\text { (x) e vertical (y) } \\
\text { Posição da partícula (x) } \\
\text { e (y) - com resistência } \\
\text { do ar } \\
\text { Posição da partícula } \\
\text { (x) e (y) - sem } \\
\text { resistência do ar } \\
\text { Variação do tempo }\end{array}$ & $\begin{array}{l}\text { Linha: } 7 \\
\text { Linhas: } 10 \text { a } 13 \\
\text { Linhas: } 10 \text { a } 13 \\
\text { Linhas: } 37 \text { e } 38 \\
\text { Linhas: } 40 \text { e } 59 \\
\text { Linhas: } 56 \text { e } 57 \\
\text { Linhas: } 14,27,33,44 \text {, } \\
\text { 52, 65, } 77 \\
\text { Linhas: } 30 \text { e } 49 \\
\text { Linhas: } 19 \text { e } 20 \\
\text { Linhas: } 31 \text { e } 32 \\
\text { Linhas: } 50 \text { e } 51 \\
\end{array}$ \\
\hline
\end{tabular}

Fonte: Dados da pesquisa

Os cálculos que simulam a trajetória do lançamento de um objeto, foram implementados em uma rotina (conceito-em-ação), identificada por calculo (teorema-em-ação). Os valores correspondentes ao ângulo, à velocidade inicial, a força gravitacional e o coeficiente da resistência do ar são informados 
na interface do programa por meio de widgets Entry (teorema-em-ação), que manipulam valores textuais. Estes dados são armazenados em variáveis do tipo float, logo precisam passar por um processo de conversão de tipos (texto para real), com a utilização da função ( float()), demonstrando os teoremas-em-ação.

No corpo da função calculo encontram-se situações que definem tomadas de decisão (conceito-emação) e que foram implementadas com o uso da instrução if (teorema-em-ação). Entre as quais se cita um teste de validação, que verifica se a simulação considerará a resistência do ar. Nestes casos o coeficiente da resistência do ar, obrigatoriamente, deve ser diferente de zero, logo, se o valor digitado for zero, o programa apresentará uma caixa de mensagem (conceito-em-ação) informando ao usuário sobre esse aspecto. No trecho do código, exibido na Figura 3, linha 14, pode-se verificar a lógica aplicada nesta tomada de decisão.

Figura 3 - Valores de entrada

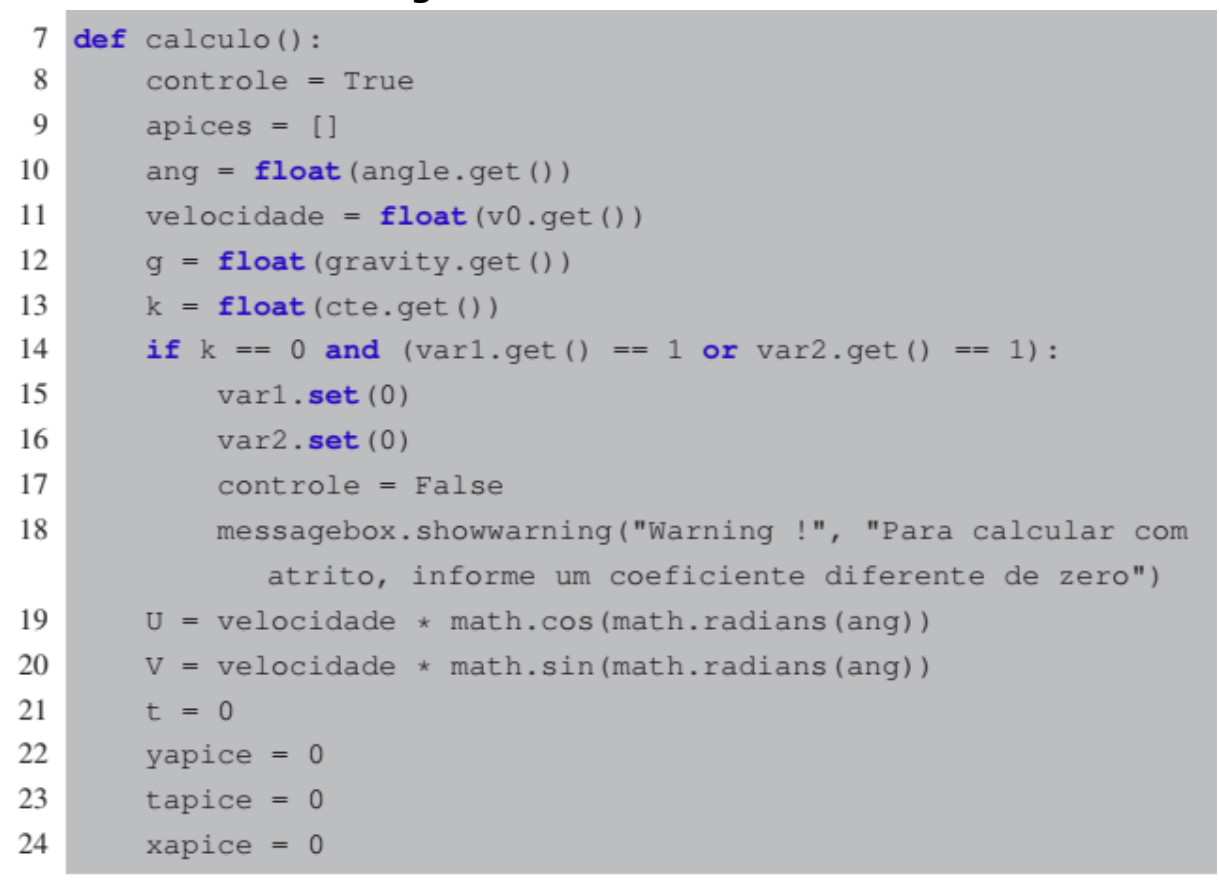

Fonte: Dados da pesquisa

O código, exibido na Figura 4, apresenta outra tomada de decisão, verificando, em uma caixa de seleção (conceito-em-ação), a consideração ou não da resistência do ar para a simulação. Caso o usuário tenha marcado a opção "Com atrito do ar", o programa executará um laço de repetição (conceito-em-ação), implementado com a aplicação da instrução while (teorema-em-ação), na qual o critério de parada será quando a coordenada y for igual a zero, indicando que o objeto atingiu o solo. Os cálculos a serem executados para as velocidades horizontal e vertical devem considerar o coeficiente $k$, que faz referência a resistência do ar, com uma variação do tempo aumentando em 0.05 segundos.

Como a altura máxima atingida pela partícula é uma informação importante para problema ela precisa ficar armazenada. Toda a vez que for calculada a coordenada y da posição, este valor será comparado com o maior valor armazenado para o y, quando o valor calculado for maior que o valor armazenado, realiza-se o armazenamento do novo valor, para as coordenadas $x$, y e o tempo em que ocorreu 0 efeito, esse armazenamento é realizado em uma estrutura de dados composta (conceito-em-ação) do tipo lista (apices). 
Figura 4 - Código que calcula as coordenadas considerando o atrito

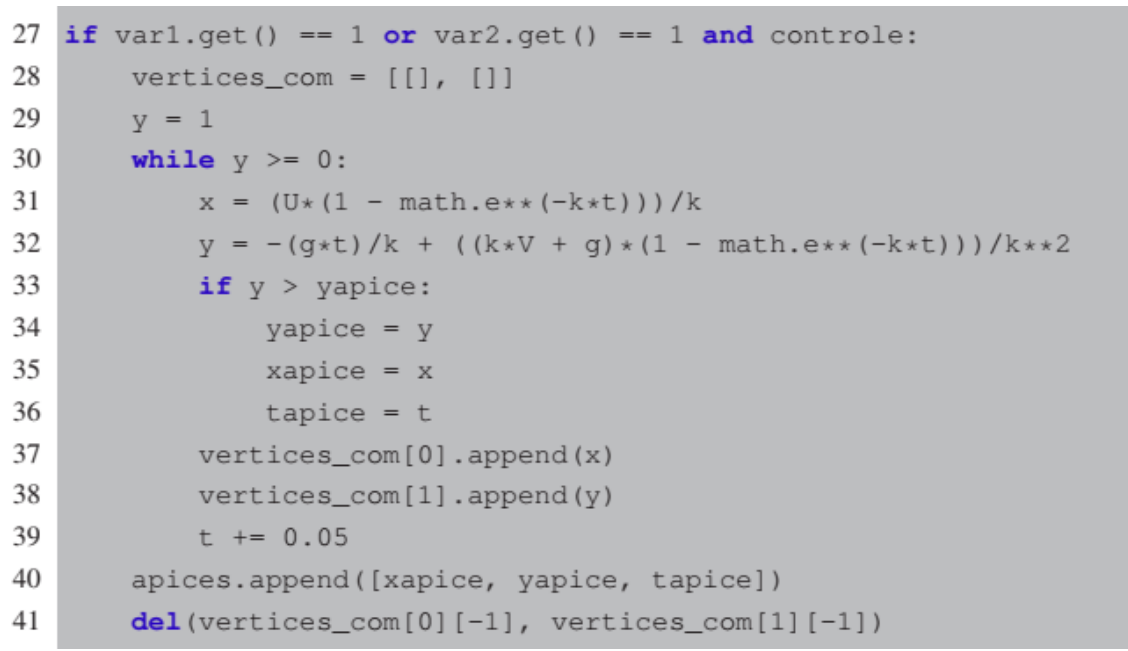

Fonte: Dados da pesquisa

O teste condicional apresentado no início do código da Figura 5, também verifica se as caixas de seleção (conceito-em-ação) estão selecionadas, neste caso para a simulação que não considera a resistência do ar. A lógica empregada nesta parte do código é muito semelhante a descrita anteriormente, que calcula as posições considerando o coeficiente de resistência do ar.

Os critérios estabelecidos para o laço de repetição, o armazenamento dos vértices (vertices sem), dos valores correspondentes ao ponto mais alto e a variação do tempo (apices) seguem o mesmo raciocínio. As principais alterações estão nos cálculos das velocidades horizontal e vertical (linhas 50 e 51), que não consideram este coeficiente.

Figura 5 - Código que calcula as coordenadas sem considerar o atrito

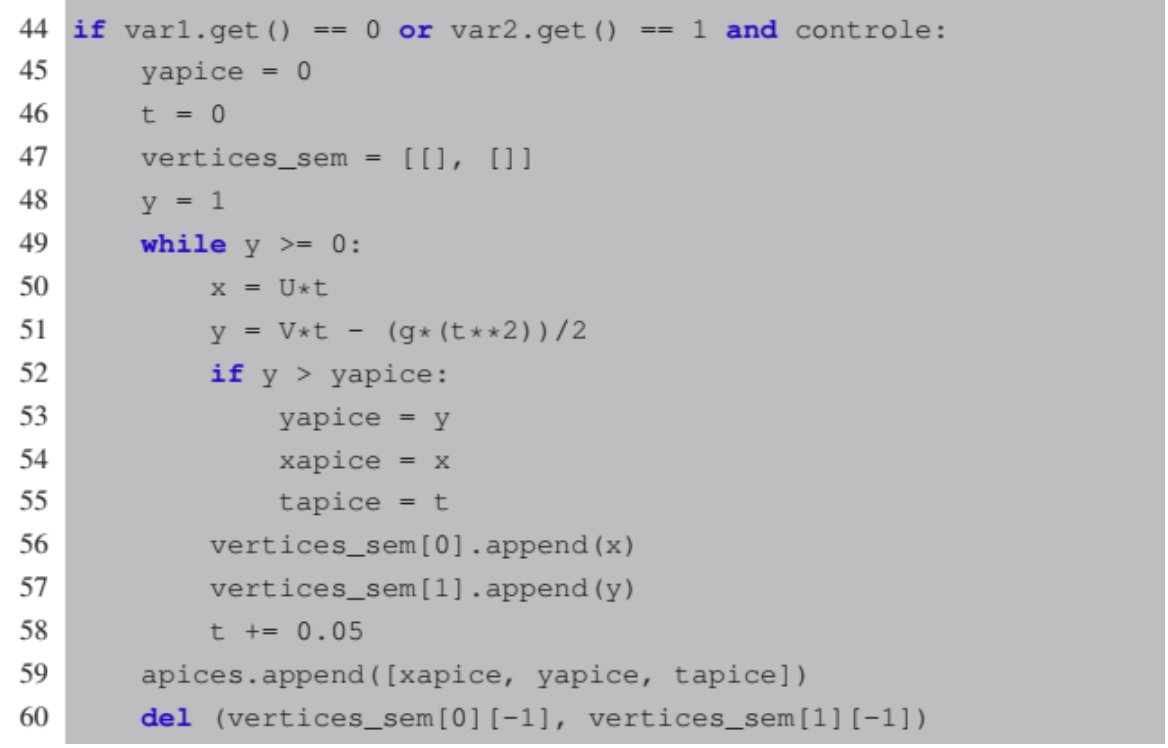

Fonte: Dados da pesquisa

Nos códigos das Figuras 4 e 5, é possível identificar a utilização de matrizes (vertices com e vertices sem) para o armazenamento dos vértices que correspondem as posições $x$ e y da partícula durante a trajetória de deslocamento. A primeira coluna armazena as coordenadas $\mathrm{x}$ e a segunda coluna as coordenadas y.

A Tabela 4 apresenta a situação que define a representação gráfica do lançamento e também foi estruturada com base com as definições da TCC. 
Tabela 4 - Campos Conceituais Programação - Lançamento Oblíquo (3)

\begin{tabular}{c|l|l|l}
\hline \multirow{2}{*}{ Situação } & \multicolumn{2}{|c|}{ Invariante operatório } & \multicolumn{1}{c}{$\begin{array}{c}\text { Representação } \\
\text { simbólica }\end{array}$} \\
\cline { 2 - 3 } Representação gráfica & \multicolumn{1}{|c}{ Conceitos-em-ação } & Teoremas-em-ação & \multicolumn{1}{c}{ Biblioteca auxiliar } \\
& Gráfico & Matplotlib & $\begin{array}{l}\text { Linha: } 4 \\
\text { Linhas: 62 e 63,66 a } \\
76,78 \text { a 82 e 84 a 89 }\end{array}$ \\
\hline
\end{tabular}

Fonte: Dados da pesquisa

A geração do gráfico que representa a trajetória da partícula também tem relação com uma tomada de decisão (conceito-em-ação). No código 6.44, na linha 65, a instrução if(teorema-em-ação) realiza um teste condicional, verificando se caixa de seleção referente ao gráfico das duas trajetórias está selecionada ou não. Em caso afirmativo os parâmetros do gráfico serão definidos para a representatividade das duas trajetórias.

Para os casos em que o usuário não marcar caixa de seleção que indica a geração dos dois gráficos, será considerada a possibilidade de simular o lançamento oblíquo com ou sem a resistência do ar. No código da Figura 6, na linha 77, encontra-se essa tomada de decisão (conceito-em-ação).

Figura 6 - Código que gera a representação gráfica do lançamento

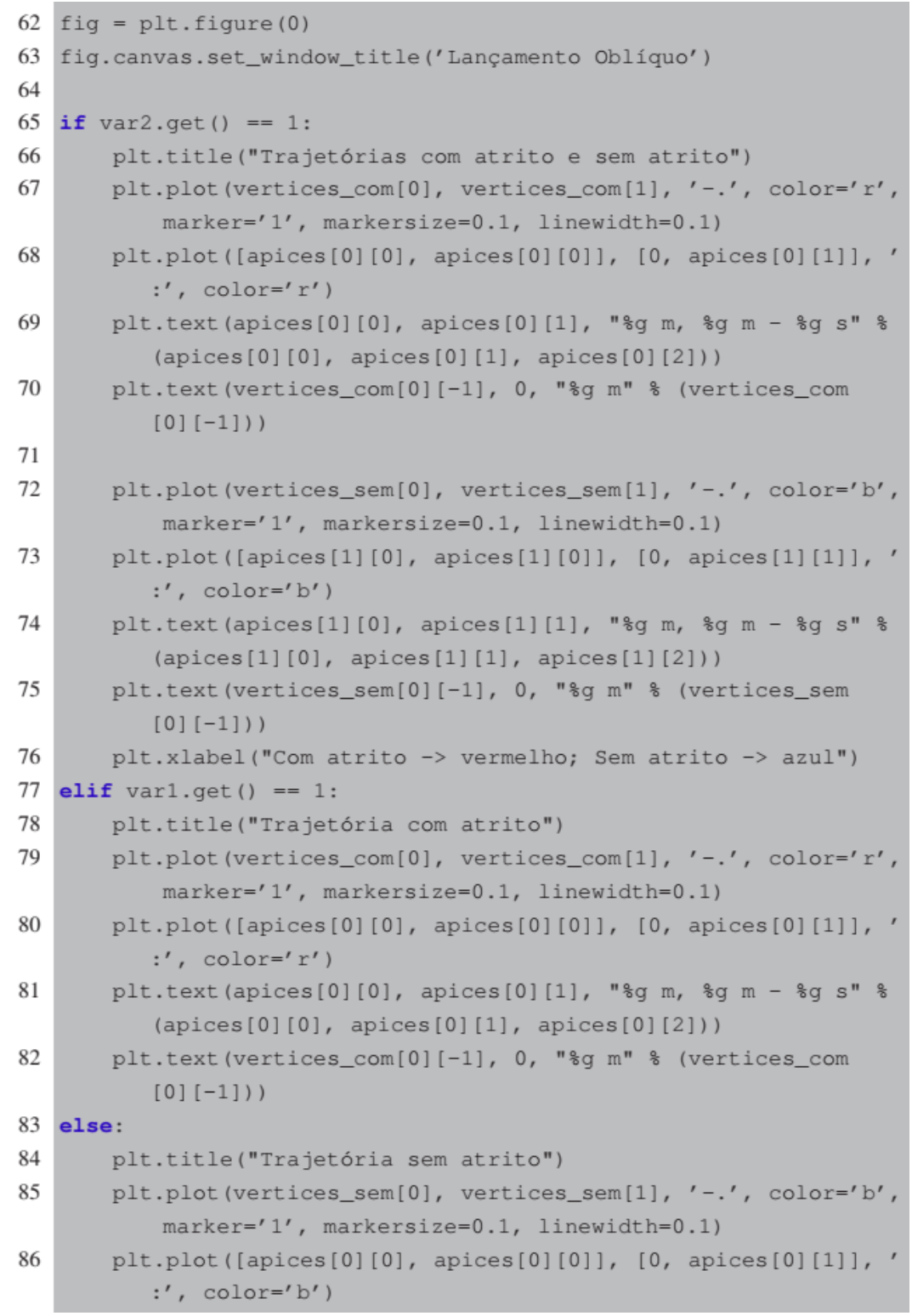

Fonte: Dados da pesquisa 
Quando o valor testado for igual a um, se têm a indicação de que a trajetória desejada é a que considera a resistência do ar. Nas ocasiões em que a caixa não for marcada, o fluxo de execução do programa será deslocado para a parte do código correspondente a simulação da trajetória sem resistência do ar. A definição dos parâmetros de configuração do gráfico obedece a cada um dos tipos de simulação.

Na Figura 7 é possível visualizar o resultado final, na forma de um gráfico, para os valores de entrada informados no exemplo. Os valores referentes à medida da altura máxima e o tempo que esse ponto foi atingido, são informações apresentadas na representação gráfica, além das duas trajetórias, uma na cor preta, que não considera a resistência do ar e outra vermelha, que leva em consideração a resistência do ar.

Figura 7 - Representação gráfica do lançamento

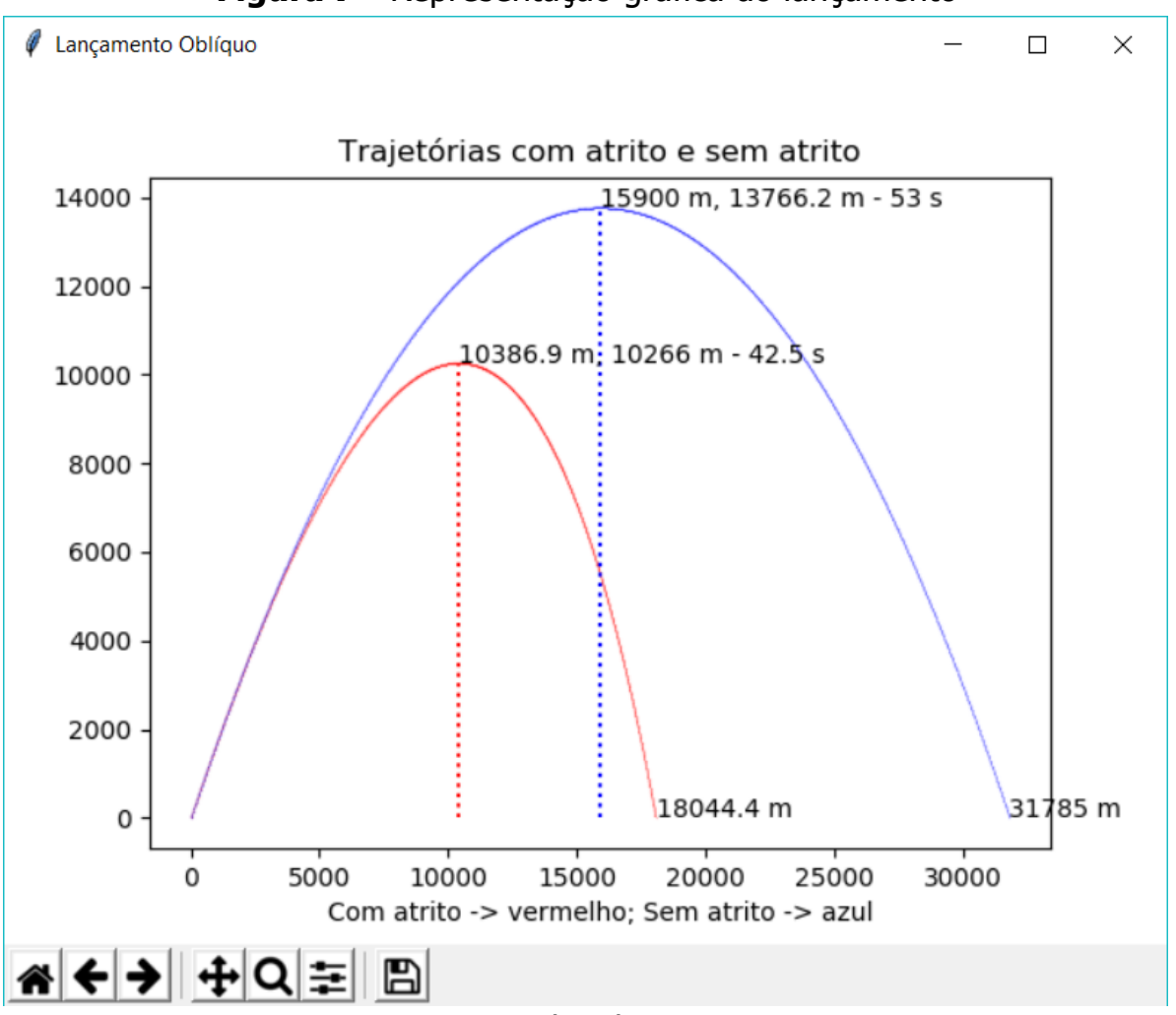

Fonte: Dados da pesquisa

A geração dos gráficos (conceito-em-ação) que ilustram as três possibilidades de visualização para as trajetórias do lançamento oblíquo, faz uso da biblioteca auxiliar (conceito-em-ação) Matplotlib (teorema-em-ação). Os recursos oferecidos pelo pacote pyplot (teorema-em-ação), atenderam perfeitamente as exigências necessárias para solucionar a situação.

\subsection{Considerações da Atividade}

Serão apresentados e comentados alguns pontos que foram relevantes durante o levantamento de dados, são respostas obtidas nas entrevistas e nos questionários e que fazem referência à resolução deste problema. Serão mostradas as questões antes das respostas dos estudantes.

No problema resolvido via programação, como conectaste o conteúdo da Física com a Programação de Computadores?

Aluno 1: Nesse problema, são usadas as fórmulas dadas no enunciado para determinar os pontos em diversos tempos, guardando a maior altura, o intervalo de tempo em que ela foi registrada. 
Aluno 2: Usando fórmulas e relações lógicas para inserir na ordem correta os cálculos e operações necessárias para escrever o código.

Aluno 3: Em relação à resolução dos problemas, a conexão foi feita através dos cálculos provindos das equações de cada conteúdo. Obviamente, com o poder de cálculo do computador e a generalização do problema, ou seja, criá-lo de uma forma que calcule qualquer resultado, era muito mais rápido de perceber a relação entre uma grandeza e outra. Além disso, com a possibilidade de criar gráficos, era muito mais fácil de visualizar os resultados obtidos com as teorias antes vistas nas aulas de Física e com fenômenos do dia a dia.

As respostas demonstram a conexão pelos estudantes indicada, inicialmente tem-se que resolver o problema pela física e após programar para obter os resultados. Alguns ajustes na programação, ou simulação de um problema, são realizados conforme a análise do resultado indicando um valor não esperado pela condição prévia imposta pela física do problema. No problema foi acrescentado uma dificuldade, que é a aproximação com uma situação do dia a dia.

Quais grandezas físicas estão envolvidas no problema?

Aluno 1: Velocidade, distância, tempo, inclinação, aceleração e resistência.

Aluno 2: Velocidade, aceleração, distância (horizontal e vertical) e resistência.

Aluno 3: Estão envolvidos o tempo (intervalo em que o projétil fica no ar), a distância (distância em que o projétil vai para cima e para frente), a velocidade (velocidade na qual o projétil sai da base), a aceleração (decorrente da força gravitacional e da força de arrasto do ar) e a constante de atrito do ar (responsável pelo quão grande era a força de atrito do ar sobre o projétil). Novamente percebiase a presença dos vetores, com os ângulos, pois esses eram decisivos no quão pra cima ou pra frente o projétil iria.

Todos os estudantes indicaram corretamente as principais grandezas física envolvidas, e o Aluno 3 acrescenta uma descrição de cada grandeza e também faz uma conexão com vetores, a qual permite perceber o uso de outras grandezas estudadas anteriormente na Física.

E como evidenciaste essas grandezas envolvidas?

Aluno 1: As grandezas estão explícitas nos enunciados, ou nas repostas.

Aluno 2: Estava explícita no enunciado.

Aluno 3: Algumas das grandezas ficavam muito visíveis na representação gráfica, principalmente a constante de atrito do ar, que mudava drasticamente a trajetória do projétil quanto maior ela fosse.

Embora sejam respostas óbvias, devido a própria circunstância de proposta do problema, o Aluno 3 percebeu que no movimento com resistência do ar a trajetória do objeto alterava drasticamente a medida que ele manipulava a constante referente ao arraste do ar. Isso indica que a programação de computadores, nessa simulação, permitiu ao estudante concluir como um fenômeno físico se altera quando alteramos algumas variáveis, ou parâmetros do problema.

No do lançamento oblíquo, com resistência do ar, foi apresentada a equação que descreve o movimento. Caso não fosse apresentada essa equação, como você resolveria o problema? Isto é, 
como você adicionaria essa dificuldade da resistência do ar, conhecendo o movimento sem resistência do ar?

Aluno 1: Eu faria o movimento frame por frame do seguinte modo: sabendo a velocidade atual do objeto, determinaria o seu próximo ponto na trajetória. Sabendo a velocidade atual do objeto e o coeficiente de arrasto, determino a parte dessa velocidade que não irá ser dissipada, usando uma função exponencial. Em seguida consideraria a aceleração para somar velocidade ao objeto.

Aluno 2: Provavelmente pesquisaria a fórmula na internet para aplicar no código.

Aluno 3: Trataria a resistência do ar como uma aceleração sempre negativa tanto no eixo X quanto no eixo $Y$, a partir de uma constante multiplicada pelo tempo. Para realizar isso, eu colocaria junto das velocidades, vertical e horizontal, ' $-k^{*} t$ ', sendo ' $k$ ' a constante de atrito e 't' o tempo decorrido. Quando digo junto, me refiro a modificar a equação sem atrito: $x=U{ }^{*} t$ para: $x=(U-k t)^{*} t$, realizando o mesmo procedimento para a equação referente ao eixo $Y$.

Observa-se pelas respostas, que o Aluno 1 e o Aluno 3 raciocinaram de forma similar. Ambos perceberam que deveria existir algum estímulo contrário ao movimento do objeto, que provocasse a redução da velocidade, e assim alterar a trajetória, comparada com a da sem resistência do ar. 0 primeiro indicou, usando a programação de computadores, que a cada passo no tempo (indicado pelo frame a frame) ele usaria o coeficiente de arrastro como um parâmetro de redução da velocidade do objeto, e supôs como solução uma função exponencial, como parte para a redução da velocidade, talvez baseado na equação que recebeu como solução do problema.

O Aluno 3 propôs uma expressão para redução da velocidade tanto na horizontal como na vertical. Embora essa proposta não seja a correta, demonstra que ele tentaria reproduzir uma resposta esperada pelo conhecimento esperado por ele para incluir a resistência do ar, indicado na frase: "Trataria a resistência do ar como uma aceleração sempre negativa...".

Ao analisar o código implementado para solucionar o problema do Lançamento Oblíquo, percebe-se que ele poderia ser melhorado, no sentido de terem sido implementadas rotinas no contexto de considerar ou não o atrito do ar, além de outra rotina responsável pela geração da representação gráfica do lançamento. Se estas medidas tivessem sido adotadas o código ficaria melhor organizado.

\section{CONCLUSÃO}

A realização desta investigação pode possibilitar a percepção de como ocorre o processo de resolução de situações problema com uso de recursos computacionais, mais especificamente da programação de computadores. A escolha deste método está relacionada com a constatação de como esta abordagem pode potencializar o processo de ensino e aprendizagem no que faz referência aos conceitos da Física, a programação de computadores e também de um aprendizado para o desempenho profissional dos estudantes.

Os resultados apresentados foram satisfatórios, os aprendizes demonstraram capacidade de construir o conhecimento, a evolução se deu de maneira gradativa frente às diferentes situações que lhes foram apresentadas. A identificação dos conceitos-em-ação, dos teoremas-em-ação e suas representações simbólicas, mostra que os estudantes conseguiram assimilar os invariantes operatórios, agregando os campos conceituais presentes em cada problema solucionado. A 
integração destes conceitos, juntamente com o entendimento e o sentido de cada conceito são fatores que indicam o desenvolvimento do aprendizado. Têm-se o discernimento de que este é um estudo preliminar, que é um projeto piloto que ainda precisa de muitas investigações e aprendizado, mas também se credencia a uma alternativa interessante que poderá produzir notáveis resultados.

O uso de recursos tecnológicos pode ajudar na compreensão de fenômenos físicos, dentre essas ferramentas aponta-se o computador, que neste trabalho foi utilizado como ponto chave, por meio da linguagem de programação Python. Os estudantes desenvolveram programas de computador para problemas relacionados a componente curricular da Física, com resultados interessantes, mostrando que com este recurso foi possível melhorar a compreensão de conceitos físicos, além de contribuir com a formação científica dos discentes.

O desenvolvimento dos programas para solucionar os problemas propostos, vem ao encontro do que se propõe a BNCC, pois os estudantes estão dinamicamente inseridos na cultura digital e além de serem consumidores devem ser também protagonistas. Como foram os próprios estudantes que escreveram os códigos e apresentaram soluções computacionais para os desafios propostos, podese identificar neste ponto a interconexão da proposta da BNCC com o uso da programação de computadores, na construção de soluções computacionais, ampliando as possibilidades de acesso à ciência e à tecnologia.

Na busca de utilizar e pôr em prática soluções que envolvem a aplicabilidade de diferentes tecnologias, em problemas complexos, depara-se com a barreira de encontrar educadores que tenham domínio sobre os conhecimentos tecnológicos, mais especificamente a programação de computadores, em nível de conseguir oferecer e compartilhar esses conhecimentos com os estudantes. É preciso pensar, discutir e investir na formação de professores, oferecendo a eles a possibilidade de aprender a desenvolver a tecnologia e de aplicar tais recursos em atividades didáticas, inovando a sala de aula.

\section{AGRADECIMENTOS}

O presente trabalho foi realizado com apoio da Coordenação de Aperfeiçoamento de Pessoal de Nível Superior - Brasil (CAPES) - Código de Financiamento 001.

\section{REFERÊNCIAS}

ALVES, C. Nelson H. et al. Jogos digitais no Ensino de Física: Estudo do Movimento Bidimensional através da Ferramenta Scratch. IV Congresso sobre Tecnologias na Educação (Ctrl+E 2019). Recife, Pernambuco - Brasil, 2019.

ANJOS, J. R. dos; FREITAS, S. dos A.; NETO, A. S. de A. Utilização do software scratch para a aprendizagem de lançamentos de projéteis e conceito de gravidade no ensino fundamental. ACTIO: Docência em Ciências. Curitiba, v. 1, n. 1, p. 128-144, jul./dez. 2016.

BRANDÃO, R. V.; ARAUJO, I. S.; VEIT, E. A. Um estudo de caso para dar sentido à tese de que a modelagem científica pode ser vista como um campo conceitual. Revista electrónica de investigación en educación en ciencias [online], v. 9, n. 1, p. 1-21, 2014. ISSN 1850-6666.

BRASIL. Etapa do ensino médio é homologada e Base Nacional Comum Curricular está completa [online]. Brasília, DF, 2018. Ministério da Educação. Disponível em: <http://portal.mec.gov.br/component/content/article?id=72011>. Acesso em: 12 dez. 2019. 
CORAL, S. R. N.; FILHO, L. P. G. Monitoria de Física do Ensino Médio: Uma Experiência de Aprendizagem. Revista de Extensão da Universidade de Cruz Alta, v. 1, n. Ano 3, p. 13, 2011.

GERMANO, E. D. T. O software Algodoo como material potencialmente significativo para o ensino de física: simulações e mudanças conceituais possíveis. 88 p. Dissertação (Mestrado em Ensino de Ciência e Tecnologia) - Pós-Graduação em Ensino de Ciência e Tecnologia. Universidade Tecnológica Federal do Paraná, Ponta Grossa, PR, 2016.

GROSSI, E. P. A Teoria dos Campos Conceituais é Algo Extraordinário! Porto Alegre, RS: Geempa, 2017. 23 p.

MELO, L. D. A.; COSTA, T. K. de L.; BATISTA, A. C. D. Pense bem: Proposta e desenvolvimento de jogo digital para ensino de computação na educação básica. In: II Congresso Brasileiro de Informática na Educação. Anais do II Congresso Brasileiro de Informática na Educação (CBIE 2013). Campinas, SP, 2013. p. 346-355.

MOREIRA, M. A. Grandes Desafios para o Ensino da Física na Educação Contemporânea. Revista do Professor de Física, v. 1, n. 1, p. 1-13, 2017.

OLIVEIRA, T. E.; ARAUJO, I. S.; VEIT, E. A. Aprendizagem Baseada em Equipes (Team-Based Learning): um método ativo para o Ensino de Física. Caderno Brasileiro de Física, v. 33, n. 3, p. 962-986, dez. 2016.

PORTO, D. A. A Inserção de Conteúdos de Física Moderna em Turmas de $3^{\circ}$ Ano do Ensino Médio Integrado do IF Sertão - PE: Uma Abordagem com Práticas Experimentais Usando Materiais de Baixo Custo. 97 p. Dissertação (Mestrado Profissional) - Programa Nacional de Mestrado Profissional em Ensino de Física (MNPEF), Universidade Federal do Vale do São Francisco, Petrolina, PE, 2015.

POZZEBON, E. et al. Programação de computadores no Ensino Médio. In: International Conference on Interactive Computer Aided Blended Learning. Anais do International Conference on Interactive Computer Aided Blended Learning - ICBL2013. Florianópolis, SC, 2013. p. 203206.

RESNICK, M. Mother's day, warrior cats, and digital fluency: Stories from the scratch online community. In: CONSTRUCTIONISM 2012. Proceedings of Constructionism 2012. Athens, Greece, 2012. p. 1-7.

SANTOS, M. B. dos. Uma Sequência Didática com os Métodos Instrução Pelos Colegas (Peer Instruction) e Ensino sob Medida (Just-in-Time Teaching) para o Estudo de Ondulatória no Ensino Médio. 174 p. Dissertação (Mestrado Profissioanal) - Programa de Pós-Graduação em Ensino de Física, Instituto de Física, Universidade Federal do Rio Grande do Sul (UFRGS), Porto Alegre, RS, 2016.

SCAICO, P. D.; LIMA, A. A. de; AZEVEDO, S.; SILVA, J. B. B. da; RAPOSO, E. H.; PAIVA, L. F.; ALENCAR, Y.; MENDES, J. P.; SCAICO, A. Ensino de programação no ensino médio: Uma abordagem orientada ao design com a linguagem scratch. Revista Brasileira de Informática na Educação, v. 21 , n. 02, p. 92, 2013. ISSN 1414-5685.

SCHITTLER, D. Laser de Rubi: Uma Abordagem em Unidades de Ensino Potencialmente Significativas (UEPS). 181 p. Tese (Doutorado) - Programa de Pós-Graduação em Ensino de Física, Instituto de Física, Universidade Federal do Rio Grande do Sul, Porto Alegre, RS, 2015. 
SOUSA, M. C. de J. O Uso da Realidade Aumentada no Ensino de Física. 135 p. Dissertação (Mestrado em Ensino de Ciências) - Programa de Pós-graduação Interunidades em Ensino de Ciências, Universidade de São Paulo (USP), São Paulo, 2015.

VERGNAUD, G. Piaget e Vygotski em Gérard Vergnaud. Porto Alegre - RS: Geempa, 2017. 85 p. ISBN 9788598022611.

VERGNAUD, G.; MOREIRA, M. A. O que é Aprender? Iceberg da Conceitualização. Porto Alegre - RS: Geempa, 2017. 121 p. ISBN 788598022628.

VIDAL, F. L. de Q.; FONTOURA, C. A. R. S. Glowscript como Ferramenta Elucidativa de Conceitos de Física: Explorando o VPython. V Congresso Nacional de Pesquisa e Ensino em Ciências CONAPESC [online] , 2020. Anais do Conapesc - ISSN: 2525-6696.

WONGWATKIT, C.; PANJABUREE, P. A proposal to develop a guided-inquiry mobile learning with a mastery learning mechanism for improving students' learning performance and atitudes in physics charoenchai. Int. J. Mobile Learning and Organisation, v. 11, n. 1, p. 63-86, 2017.

Submissão: 10/08/2021

Aceito: 13/08/2021 